\title{
Relation between bispectral index measurements of anesthetic depth and postoperative mortality: a meta-analysis of observational studies
}

\section{Relation entre les mesures de l'indice bispectral de profondeur de l'anesthésie et la mortalité postopératoire: méta-analyse des études observationnelles}

\author{
Andres Zorrilla-Vaca, BSc $\mathbb{D} \cdot$ Ryan J. Healy, BSc $\cdot$ Christopher L. Wu, MD • \\ Michael C. Grant, MD
}

Received: 11 April 2016/Revised: 12 December 2016/Accepted: 21 March 2017/Published online: 30 March 2017

(C) Canadian Anesthesiologists' Society 2017

\begin{abstract}
Introduction The association between anesthesia depth and mortality is still controversial. There are a number of narrative reviews on this topic that affirm this association, but their conclusions were based only on qualitative analyses. The aim of this meta-analysis of observational studies was to examine the potential association between depth of anesthesia as a low bispectral index (BIS) and mortality using appropriate quantitative methods.

Methods The literature was systematically reviewed in three main electronic databases (MEDLINE, EMBASE, Google Scholar) to identify all articles from inception through December 2015 regarding the association between depth of anesthesia and mortality. Inclusion criteria were restricted to observational studies that used multivariable Cox proportional regression methodology and reported adjusted hazard ratios (aHR). Pooled effect size was
\end{abstract}

This article is accompanied by an editorial. Please see Can J Anesth 2017; 64: this issue.

Electronic supplementary material The online version of this article (doi:10.1007/s12630-017-0872-6) contains supplementary material, which is available to authorized users.

A. Zorrilla-Vaca, BSc $(\bowtie) \cdot$ R. J. Healy, BSc .

C. L. Wu, MD - M. C. Grant, MD

Department of Anesthesiology and Critical Care Medicine,

Johns Hopkins University School of Medicine, $600 \mathrm{~N}$ Wolfe

Street, Phipps 455, Baltimore, MD, USA

e-mail: andres.zorrilla@correounivalle.edu.co

A. Zorrilla-Vaca, BSc

Faculty of Health, Universidad del Valle School of Medicine,

Cali, Colombia measured using a random effects model. Subgroup analysis was performed post hoc based on follow-up duration (30 days and $\geq$ one year).

Results Eight observational studies that included 40,317 patients were evaluated in this meta-analysis. The results showed a statistically significant association between the depth of anesthesia as measured by low BIS (<40-45), and mortality (pooled aHR, 1.21; 95\% CI, 1.07 to 1.38; $P=$ 0.003). Subgroup analysis showed that the association between depth of anesthesia (measured by low BIS) and mortality was significant for studies with a follow-up duration of $\geq$ one year $(n=23,347$; pooled aHR, 1.10; $95 \%$ CI, 1.00 to $1.21 ; P=0.04$ ) but was not significant for studies with a follow-up duration of 30 days $(n=16,970$; pooled aHR, 1.38; 95\% CI $=0.81$ to 2.36; $P=0.24$ ).

Conclusion Existing observational studies support a significant association between depth of anesthesia (as measured by BIS) and long-term mortality ( $\geq$ one year), although it was without statistical significance at 30 days. Larger prospective, randomized trials are necessary to establish a definitive conclusion about whether this association represents true causality or is an epiphenomenon.

\section{Résumé}

Introduction L'association entre profondeur de l'anesthésie et mortalité reste controversée. Un certain nombre d'études narratives sur ce sujet affirment que l'association existe, mais leurs conclusions étaient uniquement basées sur des analyses qualitatives. L'objectif de cette méta-analyse d'études observationnelles était d'examiner une association 
potentielle entre la profondeur de l'anesthésie sous forme d'indice bispectral (BIS) bas et la mortalité au moyen de méthodes quantitatives adaptées.

Méthodes Les publications sur trois principales bases de données électroniques (MEDLINE, EMBASE, Google Scholar) ont fait l'objet d'une recherche systématique pour identifier tous les articles concernant l'association entre profondeur de l'anesthésie et mortalité, depuis leur création jusqu'en décembre 2015. Les critères d'inclusion étaient limités aux études observationnelles ayant utilisé la méthodologie de régression multifactorielle proportionnelle de Cox et les rapports de risques rapportés ajustés (aHR). La taille de l'effet combiné a été mesurée au moyen du modèle à effets aléatoires. Une analyse post hoc de sous-groupe a été effectuée en fonction de la durée du suivi (30 jours et $\geq$ un an).

Résultats Huit études observationnelles ayant inclus 40317 patients ont été évaluées dans cette méta-analyse. Les résultats ont montré une association statistiquement significative entre la profondeur de l'anesthésie mesurée par un BIS bas $(<40$ à 45) et la mortalité (aHR combiné, 1,21; IC à $95 \%, 1,07$ à 1,38; $P=0,003)$. L'analyse de sousgroupe a montré que l'association entre la profondeur de l'anesthésie (mesurée par un BIS bas) et la mortalité était significative pour les études dont la durée de suivi était $\geq$ un an $(n=23$ 347; aHR combiné, 1, 10; IC à $95 \%, 1,00$ à 1,21; $P=0,04)$, mais elle n'était pas significative pour les études dont la durée de suivi était de 30 jours $(n=16970 ;$ aHR combiné, 1,38; IC à $95 \%=0,81$ à 2,36; $P=0,24$ ).

Conclusion Les études observationnelles existantes sont en faveur d'une association significative entre la profondeur de l'anesthésie (mesurée par le BIS) et la mortalité à long terme ( $\geq 1$ an), même s'il n'y a pas eu de signification statistique à 30 jours. De plus grandes études randomisées prospectives sont nécessaires pour parvenir à une conclusion et déterminer si cette association présente un véritable lien de causalité ou n'est qu'un épiphénomène.

Over the past decade, the role of anesthetic techniques and the use of specific drug regimens has been increasingly scrutinized to identify factors related to perioperative management that might affect certain long-term outcomes. ${ }^{1}$ One area of particular interest is the hypnotic component, or "depth of anesthesia". In decades past, depth of anesthesia was often approximated from estimates of effect-site drug concentration, spontaneous or elicited patient movement, or autonomous nervous system response. ${ }^{1,2}$ More recently, depth of anesthesia has been shown to correlate with both raw electroencephalographic (EEG) and processed EEG indices, such as the bispectral index (BIS) and spectral entropy. ${ }^{3-5}$
It remains unclear whether the depth of anesthesia itself affects perioperative outcome. Initial observational studies suggested an independent association between "low BIS" (BIS < 40-45) and patient mortality. ${ }^{6}$ Subsequent studies, however, yielded conflicting results. ${ }^{7}$ At least two narrative reviews summarized the literature on this topic, each of which reported a clinically important correlation between depth of anesthesia and mortality. ${ }^{8,9}$ However, these conclusions were based only on qualitative analyses, wherein authors provided individual interpretations of potentially disparate conclusions rather than quantifying a measured effect size. As several large trials have since been added to the literature, ${ }^{6,10-15}$ our group sought to perform a meta-analysis of the available literature in an attempt to clarify the association between depth of anesthesia (as measured by BIS) and mortality, using appropriate quantitative methods.

\section{Methods}

We have reported the results of this systematic review in accordance with recommendations of the Preferred Reporting Items for Systematic Reviews and MetaAnalyses (PRISMA) statement. ${ }^{16}$ The protocol for this review was registered (before initiation of the peer review process) at PROSPERO International Prospective Register of Systematic Reviews (CRD42016041400) - available at http://www.crd.york.ac.uk/PROSPERO/display_record.asp? ID=CRD42016041400.

\section{Search strategy}

We conducted a systematic review of the literature in three main electronic databases (MEDLINE, EMBASE, Google Scholar) to identify all articles from inception through December 2015 regarding the association between anesthesia depth (as measured by BIS) and mortality. The electronic search strategy used the terms (anesthesia depth OR anesthetic depth OR bispectral index OR spectral entropy) AND (mortality OR death). The search strategy was translated in accordance with the other database Boolean operators. Our initial literature search was not restricted to any specific study design or language designation. In addition, we reviewed citations of articles to ensure inclusion of relevant studies not captured in our initial literature search.

Study identification and selection

Publications were included if they examined the depth of anesthesia with BIS as a risk factor for mortality. For the purpose of this study, the definition of 'low BIS' could vary 
among studies but universally included BIS nadirs of $<45$. Inclusion criteria were restricted to observational studies that used multivariable Cox proportional regression modeling and reported adjusted hazard ratios (aHR). These restrictions were based on the assumption that aHR is a recommended methodology for analyzing end points that differ in time-to-event (e.g., mortality). In addition, the majority of studies on this topic have employed this methodology. Exclusion criteria were studies that did not examine anesthesia depth with BIS, those pertaining only to the intensive care unit, those reporting only odds ratios (rather than aHR), low quality studies based on the Methodological Index of Nonrandomized Studies ${ }^{6}$ (further outlined in 'Quality Assessment'), and studies that did not consider the anesthetic depth as a hypothesis for association with mortality. We also excluded randomized controlled trials (RCTs) because of their significantly smaller sample sizes compared with observational trials and their inclusion of mortality as only a secondary end point in their original trial design. These factors were likely to confound association results. We also excluded experimental studies on non-humans. When more than one publication reported data from the same patient group, we included only the most comprehensive and complete report.

\section{Subgroup analysis}

Subgroup analysis was performed post hoc based on the study's follow-up duration. The articles most often considered the short-term and long-term mortality effects as up to 30 days and more than one year, respectively. The articles that met the inclusion criteria were divided into two categories: those that examined the association with a follow-up duration of $\leq 30$ days and those that assessed the association with a follow-up duration of $>$ one year.

\section{Data extraction}

Two authors (A.Z.V., R.J.H.) independently reviewed each paper. Relevant information extracted from each study included authors, year of publication, geographic region, study design, sample size, sex distribution (percentage of male sex), American Society of Anesthesiologists physical status, follow-up duration, and mortality rate. We also took note of potential confounding variables that were adjusted for in the statistical analysis (e.g., comorbidities, age, intraoperative hypotension, type of surgery, sociodemographics).

\section{Quality assessment}

Quality assessment was performed on individual studies using the modified, validated Methodological Index of
Nonrandomized Studies (Appendix 2). ${ }^{17}$ The maximum score was 22 . Studies with a score of $\geq 18$ were considered to be of high methodological quality, and those with a score of 10-17 were considered of moderate quality. Studies with a score of $<10$ were not included, as suggested by validation studies and previous meta-analyses using this tool. ${ }^{17}$ See Appendix 1 for details.

\section{Statistical analysis}

Qualitative data of nominal variables are presented as the frequency with a percentage, where appropriate. Results reported in aHR terms were transformed in log-rank hazard ratios using recommended methods. ${ }^{18}$ Standard error was calculated using the lower and upper limits of the $95 \%$ confidence interval (CI). We estimated the adjusted pooled $\mathrm{HR}$ and the corresponding 95\% CI of the association between depth of anesthesia and mortality. Forest plots reporting aHR and 95\% CI were constructed for adjusted data and for subgroup analyses. Heterogeneity of each meta-analysis value was assessed by $I^{2}$ with the correspondent Chi-square test $\left(I^{2}<25 \%\right.$ and $I^{2}>50 \%$ were considered to have insignificant and significant heterogeneity, respectively). A $P<0.05$ (two-sided) was considered to indicate statistical significance. Publication bias was evaluated by formal testing of "funnel plot" asymmetry using Begg's and Egger's tests, with asymmetrical results considered to indicate potential bias. Begg's graph was considered symmetrical when most of the studies (scatter points) were positioned within the outer lines of the triangle (standard error represented in the $y$ axis, and $\log [\mathrm{aHR}]$ in the $\mathrm{x}$-axis) in symmetrical distribution. ${ }^{19}$ The random-effects model was used to account for possible heterogeneity between studies (DerSimonian and Laird method). ${ }^{20}$ Additionally, we performed sensitivity analysis using the leave-one-out method to ensure that inclusion of any one study did not significantly skew results. ${ }^{21}$ This method consists of serial exclusion of individual studies to assess variations in the pooled effect size. All statistical analyses were performed using Stata version 13.0 software (Stata, College Station, TX, USA).

\section{Results}

Qualitative summary

A total 1,861 studies were initially found in the literature search. After removing duplicates, screening by title/ abstract, and applying the exclusion criteria, eight studies were eligible for inclusion in this meta-analysis. The reasons for exclusion are presented in the flow chart of 


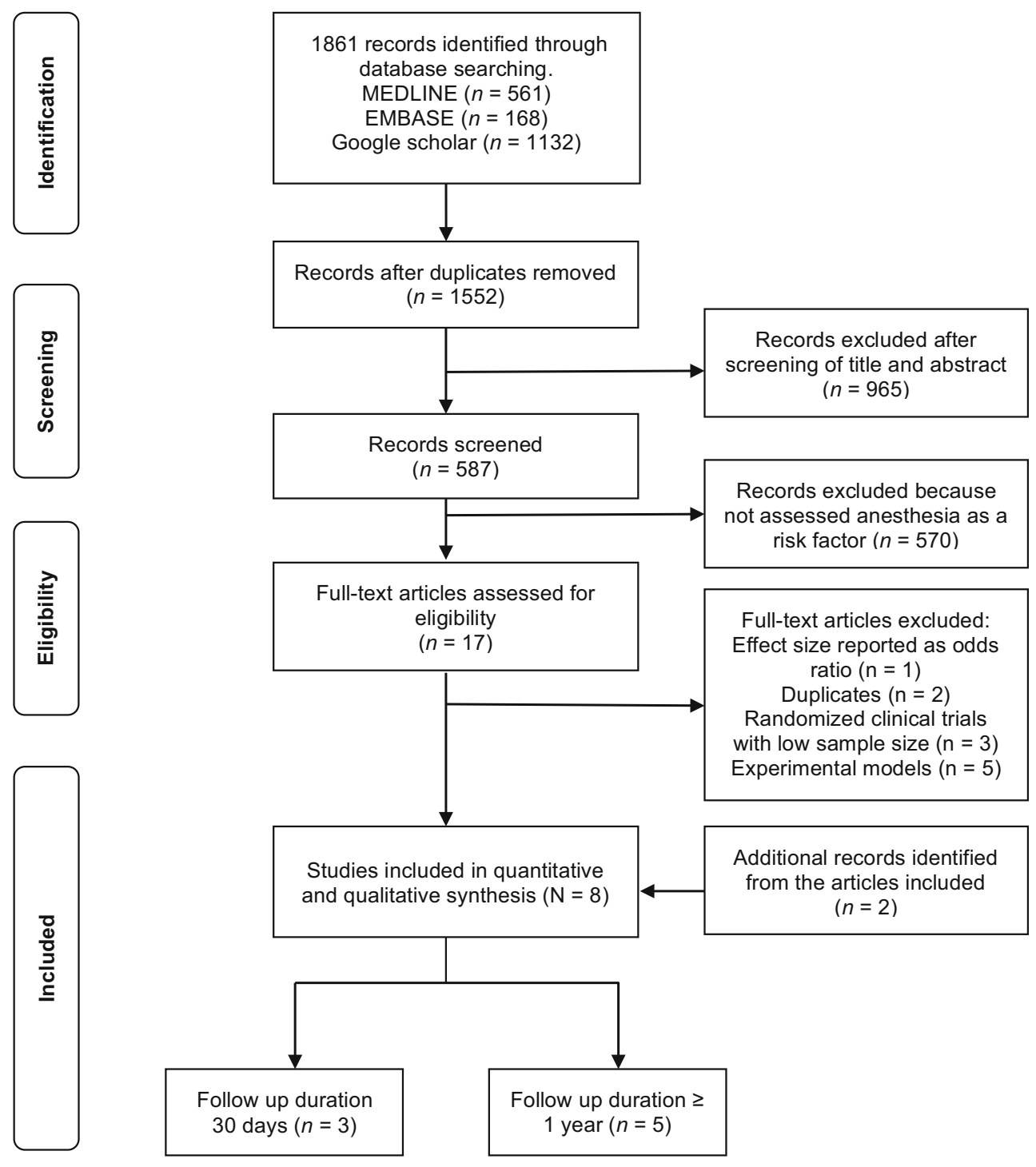

Fig. 1 PRISMA flow chart of the selection of studies

study selection in Fig. 1. ${ }^{6,10,11,13-15,22}$ Of the eight studies included, three were categorized as belonging in the shortterm follow-up group (mortality within $\leq 30$ days), and five were included in the long-term follow-up group (mortality within $>$ one year). Characteristics of the studies included are specified in the Table. Clinical risk factors included in the multivariate models of each study are reported in Appendix 2.

The study by Sessler et al. ${ }^{14}$ reported four nonoverlapping patient populations in which the authors examined the influence of the BIS with a potentially unique qualifier. This evaluation resulted in four groups of patients with combinations of low BIS $(<45)$, low mean arterial pressure (MAP $<75 \mathrm{mmHg}$ ), and low minimal alveolar concentration (MAC $<0.7)$. For the purpose of this meta-analysis, these four data sets were treated as independent studies but with an assumption of similar variance because the data were extracted from the same study population. Study quality ranged from moderate to high (scores of 18-20) (Appendix 3). No studies were excluded based on their overall quality score.

Meta-analysis and post hoc subgroup analysis

The eight studies included 40,317 patients (Table). ${ }^{6,10,11,14,15,22}$ Overall, there was a statistically significant association between low BIS and mortality (pooled aHR, 1.21; 95\% CI, 1.07 to $1.38 ; P=0.003 ; I^{2}=$ $87.4 \%$; $P$ for heterogeneity $<0.001$ ) (Fig. 2). Of note, there were two outliers. The Sessler 2012 (1) article showed a significant decrease in mortality in patients with lower BIS (HR, 0.40; 95\% CI, 0.17 to 0.94 ), and another data point from the same author (Sessler 2012 (4)) suggested a significant increase in mortality among those with lower 
Table Characteristics of the studies included in the meta-analysis

\begin{tabular}{|c|c|c|c|c|c|c|c|c|c|c|}
\hline Study, yr & $\begin{array}{l}\text { Sample } \\
\text { size }\end{array}$ & $\begin{array}{l}\text { Follow- } \\
\text { up }\end{array}$ & $\begin{array}{l}\text { Age } \\
(\mathrm{yr})\end{array}$ & $\begin{array}{l}\text { Male } \\
(\%)\end{array}$ & $\begin{array}{l}\text { ASA } \\
\geq 3, \\
(\%)\end{array}$ & $\begin{array}{l}\text { Duration of } \\
\text { anesthesia, } \\
\text { hours }(95 \% \\
\text { CI) }\end{array}$ & Definition & $\begin{array}{l}\text { Mortality } \\
\text { rate }\end{array}$ & $\begin{array}{l}\text { Adjusted } \\
\text { ratio } \\
(95 \% \mathrm{CI})\end{array}$ & Notes \\
\hline $\begin{array}{l}\text { Leslie et al. } \\
\qquad 2010^{13}\end{array}$ & 2,463 & 30 days & $\begin{array}{l}61(46- \\
71)\end{array}$ & 62 & 74 & $\begin{array}{l}3.1(1.4 \text { to } \\
4.4)\end{array}$ & $\begin{array}{l}\text { BIS }<40 \\
\quad \text { for }>5 \\
\quad \text { min }\end{array}$ & $22.2 \%$ & $\begin{array}{l}1.41 \\
(1.02 \\
\text { to } \\
1.95)\end{array}$ & $\begin{array}{l}\text { Multi-centre study in cardiac and } \\
\text { non-cardiac surgery }\end{array}$ \\
\hline $\begin{array}{l}\text { Sessler et al. } \\
\quad 2012^{14}\end{array}$ & 2,985 & 30 days & ND & ND & ND & ND & BIS $<42$ & $0.2 \%$ & $\begin{array}{l}0.40 \\
(0.17 \\
\text { to } \\
0.93)\end{array}$ & $\begin{array}{l}\text { Single-centre study in non-cardiac } \\
\text { surgery. This dataset included } \\
\text { patients with a MAP of }>82 \\
\text { mmHg and a MAC of }>0.45 \text {. }\end{array}$ \\
\hline $\begin{array}{l}\text { Sessler et al. } \\
\quad 2012^{14}\end{array}$ & 1,798 & 30 days & ND & ND & ND & ND & BIS $<42$ & $0.8 \%$ & $\begin{array}{l}1.49 \\
(0.85 \\
\text { to } \\
2.61)\end{array}$ & $\begin{array}{l}\text { Patients with a MAP of }<82 \mathrm{mmHg} \\
\text { and a MAC of }>0.45 .\end{array}$ \\
\hline $\begin{array}{l}\text { Sessler et al. } \\
\quad 2012^{14}\end{array}$ & 1,782 & 30 days & ND & ND & ND & ND & BIS $<42$ & $0.8 \%$ & $\begin{array}{l}1.90 \\
(1.08 \\
\text { to } \\
3.35)\end{array}$ & $\begin{array}{l}\text { Patients with a MAP of }>82 \mathrm{mmHg} \\
\text { and a MAC of }<0.45 .\end{array}$ \\
\hline $\begin{array}{l}\text { Sessler et al. } \\
\quad 2012^{14}\end{array}$ & 1,495 & 30 days & ND & ND & ND & ND & BIS $<42$ & $0.8 \%$ & $\begin{array}{l}3.96 \\
(2.57 \\
\text { to } \\
6.10)\end{array}$ & $\begin{array}{l}\text { Patients with a MAP of }<82 \mathrm{mmHg} \\
\text { and MAC of }<0.45 \text {. }\end{array}$ \\
\hline $\begin{array}{l}\text { Willingham } \\
\text { et al. } \\
2015^{15}\end{array}$ & 6,447 & 30 days & $\begin{array}{c}61(51- \\
70)\end{array}$ & 55.5 & 35.9 & ND & BIS $<45$ & $0.8 \%$ & $\begin{array}{l}1.00 \\
(0.45 \\
\text { to } \\
1.08)\end{array}$ & $\begin{array}{l}\text { Multi-centre study in cardiac and } \\
\text { non-cardiac surgery }\end{array}$ \\
\hline $\begin{array}{l}\text { Monk et al. } \\
2005^{22}\end{array}$ & 1,064 & $1 \mathrm{yr}$ & $\begin{array}{c}51(37- \\
65)\end{array}$ & 37 & 35 & $\begin{array}{l}3.1(2.3 \text { to } \\
4.3)\end{array}$ & BIS $<45$ & $5.5 \%$ & $\begin{array}{l}1.24 \\
(1.06 \\
\text { to } \\
1.44)\end{array}$ & $\begin{array}{l}\text { Single-centre study with non-cardiac } \\
\text { surgery }\end{array}$ \\
\hline $\begin{array}{l}\text { Lindholm } \\
\text { et al. } \\
2009^{6}\end{array}$ & 4,087 & $2 \mathrm{yr}$ & $\begin{array}{c}50(36- \\
65)\end{array}$ & 38 & 6 & $\begin{array}{l}1.8(1.2 \text { to } \\
2.5)\end{array}$ & BIS $<45$ & 4.3 & $\begin{array}{l}1.08 \\
(0.99 \\
\text { to } \\
1.18)\end{array}$ & $\begin{array}{l}\text { Single-centre study with non-cardiac } \\
\text { surgery }\end{array}$ \\
\hline $\begin{array}{l}\text { Kertai et al. } \\
\quad 2010^{10}\end{array}$ & 460 & $3 \mathrm{yr}$ & $63(13)$ & 62.4 & ND & $\begin{array}{l}6.1(5.2 \text { to } \\
7.1)\end{array}$ & BIS $<45$ & ND & $\begin{array}{l}1.29 \\
(1.12 \\
\text { to } \\
1.49)\end{array}$ & $\begin{array}{l}\text { Single-centre study with cardiac } \\
\text { surgery }\end{array}$ \\
\hline $\begin{array}{l}\text { Kertai et al. } \\
\quad 2011^{11}\end{array}$ & 1,473 & $3.2 \mathrm{yr}$ & $\begin{array}{l}57.9 \\
\quad(14.4)\end{array}$ & 50.8 & 91.7 & $\begin{array}{l}3.4(2.1 \text { to } \\
4.9)\end{array}$ & BIS $<45$ & ND & $\begin{array}{l}1.03 \\
(0.93 \\
\text { to } \\
1.14)\end{array}$ & $\begin{array}{l}\text { Single-centre study in non-cardiac } \\
\text { surgery }\end{array}$ \\
\hline $\begin{array}{l}\text { Kertai et al. } \\
\quad 2014^{12}\end{array}$ & 16,263 & $2.6 \mathrm{yr}$ & $53(16)$ & 46.7 & 45 & ND & BIS $<45$ & $9.5 \%$ & $\begin{array}{l}0.997 \\
(0.988 \\
\text { to } \\
1.007)\end{array}$ & $\begin{array}{l}\text { Single-centre study in non-cardiac } \\
\text { surgery }\end{array}$ \\
\hline
\end{tabular}

Age is reported as mean (range) or mean (standard deviation), as indicated; ASA = American Society of Anesthesiologists; BIS: bispectral index; 95\% CI = confidence interval, ND = not described in publication; MAP = mean arterial blood pressure; MAC = minimal alveolar concentration

BIS (HR, 3.96; 95\% CI, 2.57 to 6.10). The post hoc subgroup analysis suggests that the association between low BIS and mortality was not statistically significant for studies with a follow-up duration of 30 days $(n=16,970$; pooled aHR, $1.38 ; 95 \%$ CI, 0.81 to $2.36 ; P=0.24 ; I^{2}=$ 86.7\%; $P$ for heterogeneity < 0.001 ) (Fig. 3). Of note, four of the six studies originated from one author, and the outliers (as already noted) were incorporated into this analysis. In contrast, another post hoc subgroup analysis suggested that the association between low BIS and mortality was significant for studies with a follow-up duration of $\geq$ one year $(n=23,347$; pooled aHR, $1.10 ; 95 \%$ CI, 1.00 to $1.21 ; P=0.04 ; I^{2}=83.2 \%$; $P$ for heterogeneity $<0.001$ ) (Fig. 4). 
Fig. 2 Forest plot for overall comparison (using adjusted data) of the association between the depth of anesthesia and Sessler et al., ${ }^{14}$ analyzed the association using four subgroups of patients with cutoffs for the mean arterial pressure $(>82 \mathrm{mmHg}$ or $<82$ $\mathrm{mmHg}$ ) and minimum alveolar concentration $(>0.45$ or $<0.45)$ mortality. Note that the study by

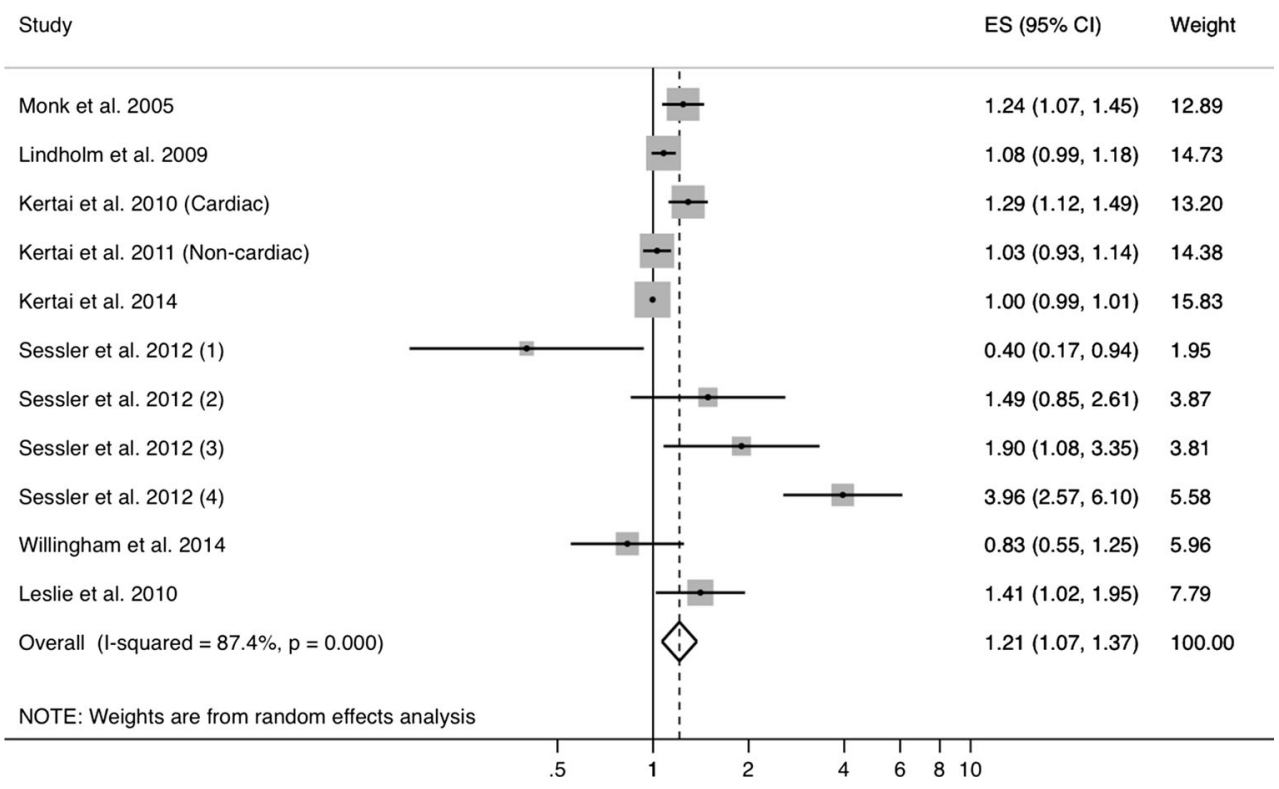

Fig. 3 Subgroup analysis, using adjusted data, of the association between the depth of anesthesia and mortality with a follow-up of 30 days

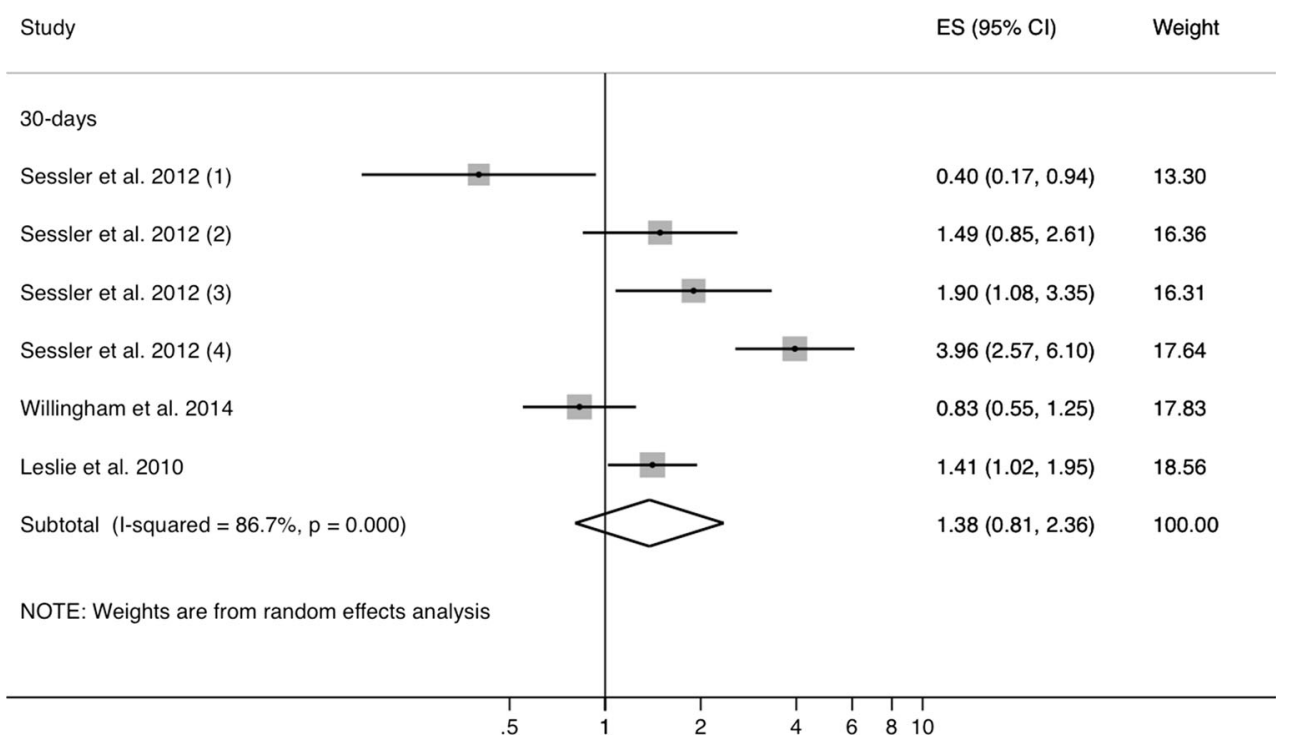

Publication bias and sensitivity analysis

For the overall meta-analysis, there was no evidence of asymmetry in the funnel plot (Begg's test, $\mathrm{z}=-0.1, P=1$ ) (Fig. 5), and there was no significant publication bias (Egger's test: bias $=1.56, P=0.31$ ) (Fig. 6). Publication bias analysis among the subgroup of studies with a 30-day follow-up resulted in no significant bias based on Egger's test (bias $=-0.7, P=0.53$ ) (Electronic Supplementary Material, Fig. 1e) or asymmetry in the funnel plot (Begg's test $\mathrm{z}=0.38, P=0.71$ ) (Electronic Supplementary Material Fig. 2e). Among the subgroup of studies with follow-up of $\geq$ one year, however, publication bias was significant based on Egger's test (bias $=2.4, P=0.04$ ) (Electronic
Supplementary Material Fig. 3e), but there was no significant asymmetry in the funnel plot (Begg's test, $\mathrm{z}=$ 1.22, $P=0.22$ ) (Electronic Supplementary Material Fig. 4e). Sensitivity analysis performed utilizing leaveone-out methodology resulted in no significant change in the pooled effect size (Electronic Supplementary Material Fig. 5e).

\section{Discussion}

The results of this meta-analysis suggest that increased anesthetic depth (as measured by BIS) was associated with significantly increased postoperative mortality at one year. 
Fig. 4 Subgroup analysis, using adjusted data, of the association between the depth of anesthesia and mortality with a follow-up of $\geq$ one year. 1) First subgroup of Sessler et al. ${ }^{14}$, with low BIS + MAP $>82$ $\mathrm{mmHg}+\mathrm{MAC}>0.45 .2$ ) Second subgroup of Sessler et al. ${ }^{14}$, with low BIS + MAP < $82 \mathrm{mmHg}+\mathrm{MAC}>0.45 .3)$ Third group of Sessler et al. ${ }^{14}$, with low BIS + MAP $>82$ $\mathrm{mmHg}+\mathrm{MAC}<0.45$. (4) Fourth group of Sessler et al. ${ }^{14}$, with low BIS + MAP $<82$ $\mathrm{mmHg}+\mathrm{MAC}<0.45$

Study

ES $(95 \% \mathrm{Cl})$

Weight
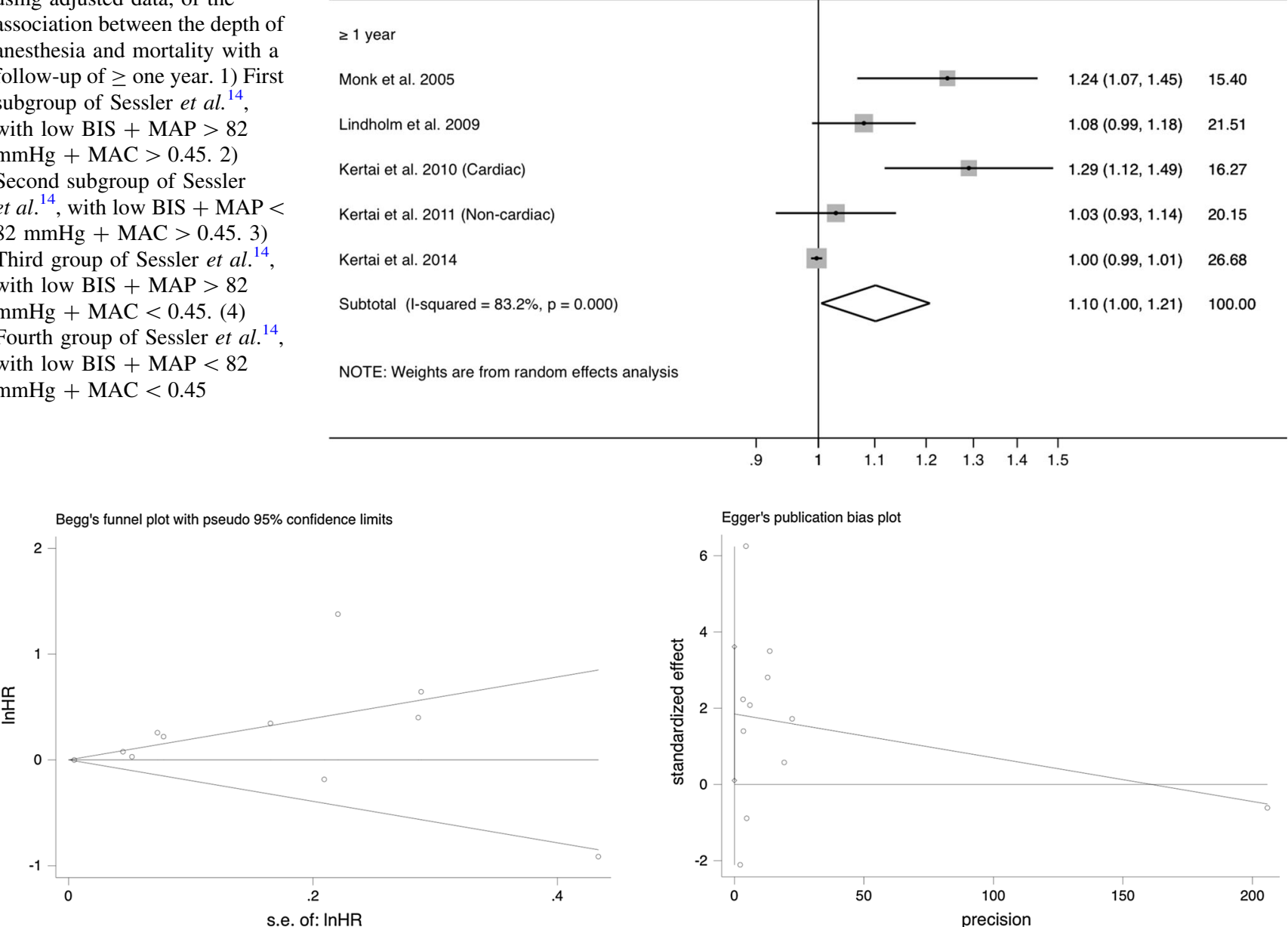

Fig. 5 Trimmed and filled funnel plot for the eight studies reporting the association of depth of anesthesia (as measured by the bispectral index) and mortality

The association remains when the relation is evaluated 30 days after surgery, although the findings did not reach statistical significance. These results are consistent with a recent systematic review. ${ }^{9}$ In addition, of all of the available literature to date, our findings are the first to be strengthened by formal quantitative analysis.

Our main finding suggesting an association between the depth of anesthesia (as measured by BIS) and mortality should be interpreted with caution. Seven of the 11 trial data sets (from the eight articles identified) used for this analysis were published by two groups of authors. Also, there were two trial data sets in Fig. 1 (each with statistically significant results) that were extreme outliers. ${ }^{14,22}$ Although post hoc subgroup analysis yielded seemingly disparate results regarding the association between low BIS and mortality, and pooled results of studies with short-term follow-up ( $\leq 30$ days) failed to

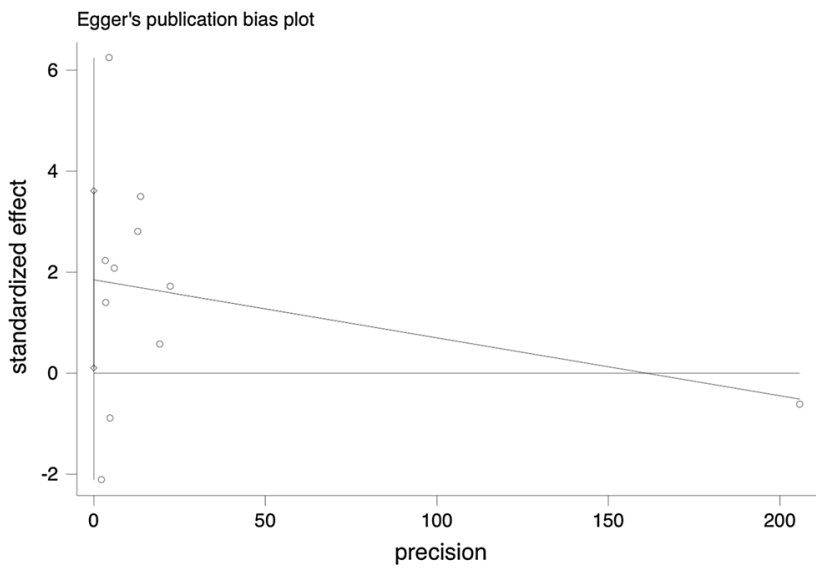

Fig. 6 Egger's publication bias for the association of studies of anesthetic depth and mortality. The diagonal line represents the regression line, and vertical line represents the $95 \%$ confidence interval for the expected distribution of studies in the absence of heterogeneity between the studies

reach statistical significance, these findings should not be considered in isolation. We could speculate that they represent a temporal association - wherein the effect size necessary to establish significance may be greater during this initial follow-up period - and therefore may simply require more patients to delineate adequately the true mortality. In point of fact, the adjusted hazard ratio for this early follow-up period was greater than that of the longerterm subgroup (aHR 1.38 vs 1.21, respectively). Despite of the results for this early group, the longer-term follow-up nevertheless suggests an association between low BIS states and subsequent mortality.

It remains unclear how anesthetic depth affects postoperative mortality. Any proposed mechanisms for linking anesthetic depth and mortality are speculative. ${ }^{15}$ It has been proposed that certain anesthetics affect long-term outcomes by activating deleterious pro-inflammatory 
pathways. $^{23,24}$ Others have outlined the dose-dependent nature of general anesthesia and subsequent immune system impairment, which, in turn, may increase susceptibility to postoperative infection ${ }^{25}$ and hasten the growth of malignant cells, leading to both metastasis and cancer recurrence. ${ }^{26-28}$ Additional factors that could explain the association between deep anesthesia and deleterious outcomes are the anesthesia-related hypotension of sedative agents, such as propofol, that could lead to organ hypoperfusion. ${ }^{29}$ As a result, there is heightened interest in establishing perioperative anesthetic pathways to improve longer-term patient outcomes, such as the use of regional techniques in Enhanced Recovery After Surgery programs, multimodal analgesia to avoid excessive sedation associated with administration of opioids alone, and asleep-awake-asleep techniques to reduce the depth of anesthesia. $^{30}$

In recent years, there has been a particular interest in exploring what components of the intraoperative management are associated with short-term or long-term mortality. ${ }^{14}$ Those studies examined the combination of $\mathrm{BIS}<45$, MAC $<0.7$, and MAP $<75 \mathrm{mmHg}$ - also known as the "triple low". This concept has been studied in three observational studies. ${ }^{12,14,15}$ Two of the studies found a statistically significant association between the "triple low" state and 30-day mortality and length of hospital stay. ${ }^{14,15}$ The third study, however, did not confirm these associations in a non-cardiac surgery population. ${ }^{12}$ Recently, Cheng et al. analyzed an alternative to the triple low phenomenon ${ }^{31}$ that replaced "low MAC" with a low effect-site concentration of propofol $(<1.5$ $\mu \mathrm{g} \cdot \mathrm{mL}^{-1}$ ) during a target-controlled infusion of the anesthetic. After adjusting for related covariates, the authors concluded that this new 'triple low state' is not associated with prolonged hospitalization but was a significant predictor of 30-day mortality. ${ }^{31}$ All of these efforts have attempted to resolve the question whether alerting clinicians about the 'triple low state' could direct changes in anesthetic management (e.g., increasing MAP, preventing low BIS, increasing MAC), resulting in decreased postoperative mortality. ${ }^{15}$

There are a number of limitations in this meta-analysis. As already noted, it is possible that certain patient populations who are more susceptible to the effects of general anesthesia are also at higher risk for mortality through an as yet unrecognized mechanism. If true, then lower BIS values may simply represent a marker for a sicker patient population or for patients undergoing higherrisk surgery. These considerations, coupled with the fact that the included studies are of observational design with post hoc analyses on non-randomized patient cohorts introduces an inherent potential for confounding. This situation may not have been adequately controlled for using the included multivariate analyses. It is thus difficult to know if anesthetic depth is the causal agent for postoperative mortality or this association simply represents an epiphenomenon. Despite best efforts to adjust for inter-study confounders, the quality of our analysis is limited to variables provided by the studies' authors. This situation further highlights the need for highquality, prospective, randomized trials in this area. Of note, there is at least one pilot RCT and at least one formal randomized trial (not included in the present analysis as we limited our study to large observational studies) devoted to this topic in patients undergoing surgery for hip fracture. $^{32,33}$ Although the results of the latter study were mixed, the authors reported a significant impact on mortality rates at one year based on patient-related comorbidities. To our knowledge, there is a currently ongoing large RCT called the BALANCED anesthesia study (available from: https://clinicaltrials.gov/ct2/show/ NCT02073357) that has enrolled more than 6,000 patients and has the main objective of clarifying the association between depth of anesthesia and mortality. All of these advances may introduce further research opportunities for better understanding the interplay between individual patient characteristics and anesthetic approaches.

Although observational trials may provide opportunities to evaluate weaknesses associated with small, prospective, randomized trials, our results should be interpreted with caution given the high degree of heterogeneity in the results. Despite this observed heterogeneity, the quality of the conducted studies was considered moderate to high. Finally, although we did not provide evidence of significant publication bias, it should be noted that our meta-analysis was likely underpowered to test adequately for publication bias in selected subgroups.

In summary, pooled analysis of existing observational studies support a significant association between depth of anesthesia (as measured by BIS) and long-term mortality, although it was not statistically significant at 30 days after surgery based on the available data - which were insufficient to bestow the high power needed. Given the above association, further large, prospective, randomized trials could provide significant clarity on this topic. In an era of increased recognition of the long-term impact of acute care, the results of this review suggest that patients could potentially benefit from the recognition of comprehensive, goal-directed, perioperative pathways to avoid excessive anesthetic depth.

Acknowledgements We thank the staff at the William H. Welch Medical Library, with whom we consulted when conducting the literature review for this analysis. We also thank the staff at the Biostatistics Department at the Johns Hopkins Bloomberg School of Public Health, with whom we consulted regarding the statistical analyses. 
Conflicts of interest None declared.

Editorial responsibility This submission was handled by Dr. Hilary P. Grocott, Editor-in-Chief, Canadian Journal of Anesthesia.

Author contributions Andres Zorrilla-Vaca and Michael C. Grant contributed substantially to all aspects of this manuscript, including conception and design; acquisition, analysis, and interpretation of data; and drafting the article. Christopher $L$. $W u$ contributed substantially to the conception and design of the manuscript. Ryan $J$. Healy contributed substantially to the acquisition of data.

\section{Appendix 1}

Modified 11-Item Methodological Index for Nonrandomized Studies tool $^{17}$

\begin{tabular}{|c|c|c|}
\hline No. & Item & Explanation \\
\hline 1 & A clearly stated aim & $\begin{array}{l}\text { The question addressed should } \\
\text { be precise and relevant in } \\
\text { the light of available } \\
\text { literature. }\end{array}$ \\
\hline 2 & $\begin{array}{l}\text { Inclusion of } \\
\text { consecutive patients }\end{array}$ & $\begin{array}{l}\text { All patients potentially fit for } \\
\text { inclusion (satisfying the } \\
\text { criteria for inclusion) have } \\
\text { been included in the study } \\
\text { during the study period (no } \\
\text { exclusion or details about } \\
\text { the reasons for exclusion). }\end{array}$ \\
\hline 3 & $\begin{array}{l}\text { Prospective collection } \\
\text { of data }\end{array}$ & $\begin{array}{l}\text { Data were collected according } \\
\text { to a protocol established } \\
\text { before the beginning of the } \\
\text { study. }\end{array}$ \\
\hline 4 & $\begin{array}{l}\text { Appropriate definition } \\
\text { of the outcome }\end{array}$ & $\begin{array}{l}\text { Unambiguous explanation of } \\
\text { the criteria used to evaluate } \\
\text { the main outcome, which } \\
\text { should be in accordance } \\
\text { with the question addressed } \\
\text { by the study. Also, outcome } \\
\text { should be based on } \\
\text { authoritative concepts. }\end{array}$ \\
\hline 5 & $\begin{array}{l}\text { Unbiased assessment } \\
\text { of the outcome }\end{array}$ & $\begin{array}{l}\text { Blind evaluation of objective } \\
\text { endpoints and double-blind } \\
\text { evaluation of subjective } \\
\text { endpoints. Otherwise the } \\
\text { reasons for not blinding } \\
\text { should be stated. }\end{array}$ \\
\hline 6 & Definition of exposure & $\begin{array}{l}\text { Unambiguous explanation of } \\
\text { the criteria used to evaluate } \\
\text { the main exposure, which } \\
\text { should be in accordance } \\
\text { with the question addressed } \\
\text { by the study. }\end{array}$ \\
\hline 7 & $\begin{array}{l}\text { Follow-up period } \\
\text { appropriate to the } \\
\text { aim of the study }\end{array}$ & $\begin{array}{l}\text { The follow-up should be } \\
\text { sufficiently long to allow } \\
\text { the assessment of the main } \\
\text { endpoint and possible } \\
\text { adverse events. }\end{array}$ \\
\hline
\end{tabular}

\begin{tabular}{lll}
\hline No. Item & Explanation & Score* \\
\hline
\end{tabular}

8 Loss to follow-up All patients should be included in less than $5 \%$ the follow up. Otherwise, the proportion lost to follow up should not exceed the proportion experiencing the major endpoint.

9 Prospective Information of the size of calculation of the detectable difference of interest study size with a calculation of $95 \%$ confidence interval, according to the expected incidence of the outcome event.

10 Adequate statistical Whether the statistics were in analysis accordance with the type of study with calculation of confidence intervals or relative risk.

11 Management for Use of multivariate analysis potential confounders

* The items are scored 0 (not reported), 1 (reported but inadequate) or 2 (reported and adequate). The global ideal score being 20 using this modified tool for quality assessment

\section{Appendix 2}

Multivariate models used by each study included in this meta-analysis

\begin{tabular}{|c|c|}
\hline Study & Risk factors adjusted for \\
\hline $\begin{array}{l}\text { Monk et al., } \\
2005 .^{22}\end{array}$ & $\begin{array}{l}\text { ASA physical status, age, comorbidities, history of } \\
\text { hepatic disease, previous myocardial infarction, } \\
\text { hypertension, surgical duration, intraoperative } \\
\text { systolic pressure, BMI, preoperative diastolic } \\
\text { blood pressure, education level, type of surgery, } \\
\text { mini-mental state examination. }\end{array}$ \\
\hline $\begin{array}{l}\text { Lindholm et al., } \\
2009{ }^{6}\end{array}$ & $\begin{array}{l}\text { Age, gender, BMI, ASA, type of surgery, cancer } \\
\text { status before surgery. }\end{array}$ \\
\hline $\begin{array}{l}\text { Kertai et al., } \\
2010 .{ }^{10}\end{array}$ & $\begin{array}{l}\text { Smoking history, chronic medication use, } \\
\text { euroscore, preoperative hemoglobin, duration } \\
\text { anesthesia, duration cardiopulmonary bypass, } \\
\text { mean arterial pressure, transfusion, fresh frozen } \\
\text { plasma, platelets units, anesthesia-related } \\
\text { intraoperative infusion, intensive care unit stay. }\end{array}$ \\
\hline $\begin{array}{l}\text { Kertai et al., } \\
\text { 2014. }^{12}\end{array}$ & $\begin{array}{l}\text { Age, gender, ASA physical status, Cleveland } \\
\text { Clinic Risk Index score, type of surgery, } \\
\text { duration of surgery, year of surgery. }\end{array}$ \\
\hline $\begin{array}{l}\text { Leslie } \text { et al., } \\
2^{1010 .}\end{array}$ & $\begin{array}{l}\text { Age, gender, weight, ASA physical status, cardiac } \\
\text { surgery, emergency surgery, omission of } \mathrm{N}_{2} \mathrm{O} \text {, } \\
\text { propofol maintenance, randomization to BIS, } \\
\text { severe hypotension, surgery duration. }\end{array}$ \\
\hline
\end{tabular}




\begin{tabular}{|c|c|}
\hline Study & Risk factors adjusted for \\
\hline Kertai et al., $2011 .^{11}$ & $\begin{array}{l}\text { Age, gender, BMI, smoking history, } \\
\text { medical history, diabetes mellitus, } \\
\text { chronic medication use, preoperative } \\
\text { hemoglobin, surgery type, indication } \\
\text { for surgery, ASA, duration of } \\
\text { anesthesia, intraoperative } \\
\text { hypotension, tachycardia, fluid } \\
\text { management, intensive care unit stay. }\end{array}$ \\
\hline Sessler et al., $2012 .{ }^{14}$ & $\begin{array}{l}\text { Risk stratification index, } \mathrm{ASA}, \mathrm{N}_{2} \mathrm{O} \\
\text { administration, mean propofol rate, } \\
\text { transfusion, case duration, age, } \\
\text { gender, race, BMI. }\end{array}$ \\
\hline $\begin{array}{l}\text { Willingham et al., } \\
\text { Willingham et al., } \\
\text { 2015. }\end{array}$ & $\begin{array}{l}\text { Age, gender, ASA physical status, MAC, } \\
\mathrm{N}_{2} \mathrm{O} \text { administration, cardiopulmonary } \\
\text { bypass, history of coronary artery } \\
\text { disease, congestive heart failure, } \\
\mathrm{COPD} \text {, cancer, pulmonary } \\
\text { hypertension, cardiac valvular disease, } \\
\text { use of GABA drugs, anticonvulsants } \\
\text { use, opioids. }\end{array}$ \\
\hline
\end{tabular}

ASA = American society of anesthesiologists, $\mathrm{BMI}=$ body mass index, $\mathrm{COPD}=$ chronic obstructive pulmonary disease, GABA = gamma-aminobutyric acid, MAC $=$ minimal alveolar concentration

\section{Appendix 3}

Methodological assessment of the studies included in the metaanalysis

\begin{tabular}{|c|c|c|c|c|c|c|c|c|c|c|c|c|}
\hline \multirow[t]{2}{*}{ Study } & \multicolumn{11}{|c|}{ Item* } & \multirow{2}{*}{$\begin{array}{l}\text { Total } \\
\text { score }\end{array}$} \\
\hline & 1 & 2 & 3 & 4 & 5 & 6 & 7 & 8 & 9 & 10 & 11 & \\
\hline $\begin{array}{l}\text { Monk et al., } \\
2005 .^{22}\end{array}$ & 2 & 2 & 1 & 2 & 1 & 2 & 2 & 1 & 1 & 2 & 2 & 18 \\
\hline $\begin{array}{l}\text { Lindholm et al., } \\
2009 .{ }^{6}\end{array}$ & 2 & 2 & 1 & 2 & 1 & 2 & 2 & 1 & 1 & 2 & 2 & 18 \\
\hline $\begin{array}{l}\text { Kertai et al., } \\
2010 .^{10}\end{array}$ & 2 & 2 & 1 & 2 & 1 & 2 & 2 & 2 & 1 & 2 & 2 & 19 \\
\hline $\begin{array}{l}\text { Kertai et al., } \\
2^{2014 .} .^{12}\end{array}$ & 2 & 2 & 1 & 2 & 1 & 2 & 2 & 2 & 1 & 2 & 2 & 19 \\
\hline $\begin{array}{l}\text { Leslie } e t \text { al. } \\
2010 .^{13}\end{array}$ & 2 & 2 & 1 & 2 & 1 & 2 & 2 & 2 & 2 & 2 & 2 & 20 \\
\hline $\begin{array}{l}\text { Kertai et al., } \\
\quad 2011 .{ }^{11}\end{array}$ & 2 & 2 & 1 & 2 & 1 & 2 & 2 & 2 & 1 & 2 & 2 & 19 \\
\hline $\begin{array}{l}\text { Sessler et al., } \\
\quad 2012 .{ }^{14}\end{array}$ & 2 & 2 & 1 & 2 & 1 & 2 & 2 & 2 & 2 & 2 & 2 & 20 \\
\hline $\begin{array}{l}\text { Willingham } \\
\quad \text { et al., } 2015 .{ }^{15}\end{array}$ & 2 & 2 & 1 & 2 & 1 & 2 & 2 & 2 & 2 & 2 & 2 & 20 \\
\hline
\end{tabular}

* Each item is described in the Methodology section

\section{References}

1. Kent $C D$, Domino $K B$. Depth of anesthesia. Curr Opin Anaesthesiol 2009; 22: 782-7.

2. Yu L, Sun H, Yao L, Feng Y. An approach to using central pupils as a clinical sign to assess depth of anesthesia in infants undergoing fundus examination with inhalation of sevoflurane. $\mathrm{J}$ Clin Anesth 2016; 29: 5-9.

3. Bowdle TA. Depth of anesthesia monitoring. Anesthesiol Clin 2006; 24: 793-822.

4. $L i T N, L i Y$. Depth of anaesthesia monitors and the latest algorithms. Asian Pac J Trop Med 2014; 7: 429-37.

5. Purdon PL, Sampson A, Pavone KJ, Brown EN. Clinical electroencephalography for anesthesiologists: part i: background and basic signatures. Anesthesiology 2015; 123: 937-60.

6. Lindholm ML, Traff S, Granath F, et al. Mortality within 2 years after surgery in relation to low intraoperative bispectral index values and preexisting malignant disease. Anesth Analg 2009; 108: 508-12.

7. Drummond JC. Depth of anesthesia causality dilemmas: the next generation. Can J Anesth 2016; 63: 142-7.

8. Escallier KE, Nadelson MR, Zhou D, Avidan MS. Monitoring the brain: processed electroencephalogram and peri-operative outcomes. Anaesthesia 2014; 69: 899-910.

9. Leslie $K$, Short TG. Anesthetic depth and long-term survival: an update. Can J Anesth 2016; 63: 233-40.

10. Kertai MD, Pal N, Palanca BJ, et al. Association of perioperative risk factors and cumulative duration of low bispectral index with intermediate-term mortality after cardiac surgery in the BUnaware Trial. Anesthesiology 2010; 112: 1116-27.

11. Kertai MD, Palanca BJ, Pal $N$, et al. Bispectral index monitoring, duration of bispectral index below 45 , patient risk factors, and intermediate-term mortality after noncardiac surgery in the B-Unaware Trial. Anesthesiology 2011; 114: 545-56.

12. Kertai MD, White WD, Gan TJ. Cumulative duration of "triple low" state of low blood pressure, low bispectral index, and low minimum alveolar concentration of volatile anesthesia is not associated with increased mortality. Anesthesiology 2014; 121: 18-28.

13. Leslie K, Myles PS, Forbes A, Chan MT. The effect of bispectral index monitoring on long-term survival in the B-Aware Trial. Anesth Analg 2010; 110: 816-22.

14. Sessler DI, Sigl JC, Kelley SD, et al. Hospital stay and mortality are increased in patients having a "triple low" of low blood pressure, low bispectral index, and low minimum alveolar concentration of volatile anesthesia. Anesthesiology 2012; 116: 1195-203.

15. Willingham MD, Karren E, Shanks AM, et al. Concurrence of intraoperative hypotension, low minimum alveolar concentration, and low bispectral index is associated with postoperative death. Anesthesiology 2015; 123: 775-85.

16. Moher D, Liberati A, Tetzlaff J, Altman DG, PRISMA Group. Preferred reporting items for systematic reviews and metaanalyses: the PRISMA statement. PLoS Med 2009; 6: e1000097.

17. Slim K, Nini E, Forestier D, Kwiatkowski F, Panis $Y$, Chipponi J. Methodological index for non-randomized studies (minors): development and validation of a new instrument. ANZ J Surg 2003; 73: 712-6.

18. Stroup DF, Berlin JA, Morton SC, et al. Meta-analysis of observational studies in epidemiology: a proposal for reporting. 
Meta-analysis Of Observational Studies in Epidemiology (MOOSE) group. JAMA 2000; 283: 2008-12.

19. Sterne JA, Sutton AJ, Ioannidis JP, et al. Recommendations for examining and interpreting funnel plot asymmetry in metaanalyses of randomised controlled trials. BMJ 2011; 343: d4002.

20. DerSimonian R, Laird $N$. Meta-analysis in clinical trials. Control Clin Trials 1986; 7: 177-88.

21. Higgins JP. Commentary: Heterogeneity in meta-analysis should be expected and appropriately quantified. Int J Epidemiol 2008; 37: 1158-60.

22. Monk TG, Saini V, Weldon BC, Sigl JC. Anesthetic management and one-year mortality after noncardiac surgery. Anesth Analg 2005; 100: 4-10.

23. Crozier TA, Muller JE, Quittkat D, Sydow M, Wuttke W, Kettler $D$. Effect of anaesthesia on the cytokine responses to abdominal surgery. Br J Anaesth 1994; 72: 280-5.

24. Kudoh A, Katagai H, Takazawa T, Matsuki A. Plasma proinflammatory cytokine response to surgical stress in elderly patients. Cytokine 2001; 15: 270-3.

25. Zorrilla-Vaca A, Arevalo JJ, Escandon-Vargas K, Soltanifar D, Mirski MA. Infectious disease risk associated with contaminated propofol anesthesia, 1989-2014. Emerg Infect Dis 2016; 22: 98192.

26. Byrne K, Levins KJ, Buggy DJ. Can anesthetic-analgesic technique during primary cancer surgery affect recurrence or metastasis? Can J Anesth 2016; 63: 184-92.
27. Salo $M$. Effects of anaesthesia and surgery on the immune response. Acta Anaesthesiol Scand 1992; 36: 201-20.

28. Snyder GL, Greenberg S. Effect of anaesthetic technique and other perioperative factors on cancer recurrence. $\mathrm{Br} \mathrm{J}$ Anaesth 2010; 105: 106-15.

29. Campos $S$, Felix L, Venancio $C$, et al. In vivo study of hepatic oxidative stress and mitochondrial function in rabbits with severe hypotension after propofol prolonged infusion. Springerplus 2016; 5: 1349.

30. Fawcett WJ, Baldini G. Optimal analgesia during major open and laparoscopic abdominal surgery. Anesthesiol Clin 2015; 33: 6578.

31. Cheng $X Q, W u H, Z$ uo $Y M$, et al. Perioperative risk factors and cumulative duration of "triple-low" state associated with worse 30-day mortality of cardiac valvular surgery. J Clin Monit Comput 2016. DOI:10.1007/s10877-016-9856-2.

32. Brown CH 4th, Azman AS, Gottschalk A, Mears SC, Sieber FE. Sedation depth during spinal anesthesia and survival in elderly patients undergoing hip fracture repair. Anesth Analg 2014; 118: 977-80.

33. Short TG, Leslie $K$, Campbell D, et al. A pilot study for a prospective, randomized, double-blind trial of the influence of anesthetic depth on long-term outcome. Anesth Analg 2014; 118: 981-6. 